\title{
Aspects of interhemispheric subdural haematoma, including the falx syndrome
}

\author{
J A M ES S. OGSBURY, ST UARTA. SCHNECK, A N D \\ R A L PH A. W. LEH M A N \\ From the Division of Neurosurgery and the Department of Neurology, University of Colorado \\ Medical Center, Denver, Colorado, USA
}

SUMMARY Two cases of interhemispheric subdural haematoma are reported. The first patient presented with a falx syndrome of contralateral hemiparesis, most marked in the lower extremity. The second patient had vertex headaches and was diagnosed with computerised tomography. Serial studies suggested that the interhemispheric haematoma may have migrated to a lateral position over the cerebral convexity.

Although subdural haematomas generally occur over the convexity of the hemispheres, they occasionally present in the interhemispheric fissure (Aring and Evans, 1940; Jacobsen, 1955; Gannon, 1961; Wollschlaeger and Wollschlaeger, 1964; Isfort, 1967; Clein and Bolton, 1969; Sibayan et al., 1970). In the past, the importance of cerebral angiography has been emphasised in these cases (Jacobsen, 1955; Gannon, 1961; Wollschlaeger and Wollschlaegar, 1964; Isfort, 1967; Clein and Bolton, 1969; Sibayan et al., 1970). We have recently had the opportunity to treat two patients with interhemispheric subdural haematomas. The first patient presented with a constellation of signs and symptoms which might have pointed to the diagnosis before angiography. The diagnosis in the second case was made by computerised tomography.

\section{Case reports}

\section{CASE 1}

A 70 year old physician was well until she was knocked over by her dog and struck her occiput on a table without losing consciousness. Three hours later she developed a diffuse headache, and subsequently became nauseated and vomited. Neurological examination 24 hours later was entirely normal. However intermittent headache and vomiting persisted, and, 36 hours after injury,

Address for reprint requests: Dr Ralph A.W. Lehman, Division of Neurosurgery, University of Colorado Medical Center, 4200 E. 9th Avenue, Denver, Co. 80262, USA.

Accepted 9 August 1977 she developed numbness and weakness of her left leg and then her left arm. Examination at that time revealed a blood pressure of $152 / 80 \mathrm{mmHg}$ and a pulse rate of 60 per minute. She was alert and fully oriented, and had normal fundi, pupils and extraocular movements. There was a left hemiparesis, severe in the leg, mild in the armo and minimal in the face. Deep tendon reflexes were slightly less brisk on the left than theo right. Sensation was intact. Skull radiographs were normal with the pineal calcification in the midline.

In view of the dramatic leg paresis in the face of a normal mental status it was thought that she might have developed an anterior cerebral artery thrombosis as a result of dehydration secondary to vomiting. The possibility of a post-traumatic intracranial haematoma was considered to be less likely. Twelve hours after admission left sided seizures occurred predominantly in the lower extremity. Angiography disclosed a right interhemispheric mass (Figs. 1 and 2), and was followed by a craniotomy with subtotal removal of an interhemispheric blood clot extending the length of the falx. Postoperatively she was somnolent and required tracheotomy but gradually improved, and was discharged 25 days after surgery. By three months after the operation she had recovered her normal leg strength and was beginning to resume full professional activities.

CASE 2

A 44 year old man suffered a blow to the head during a wrestling match. He was not knocked 


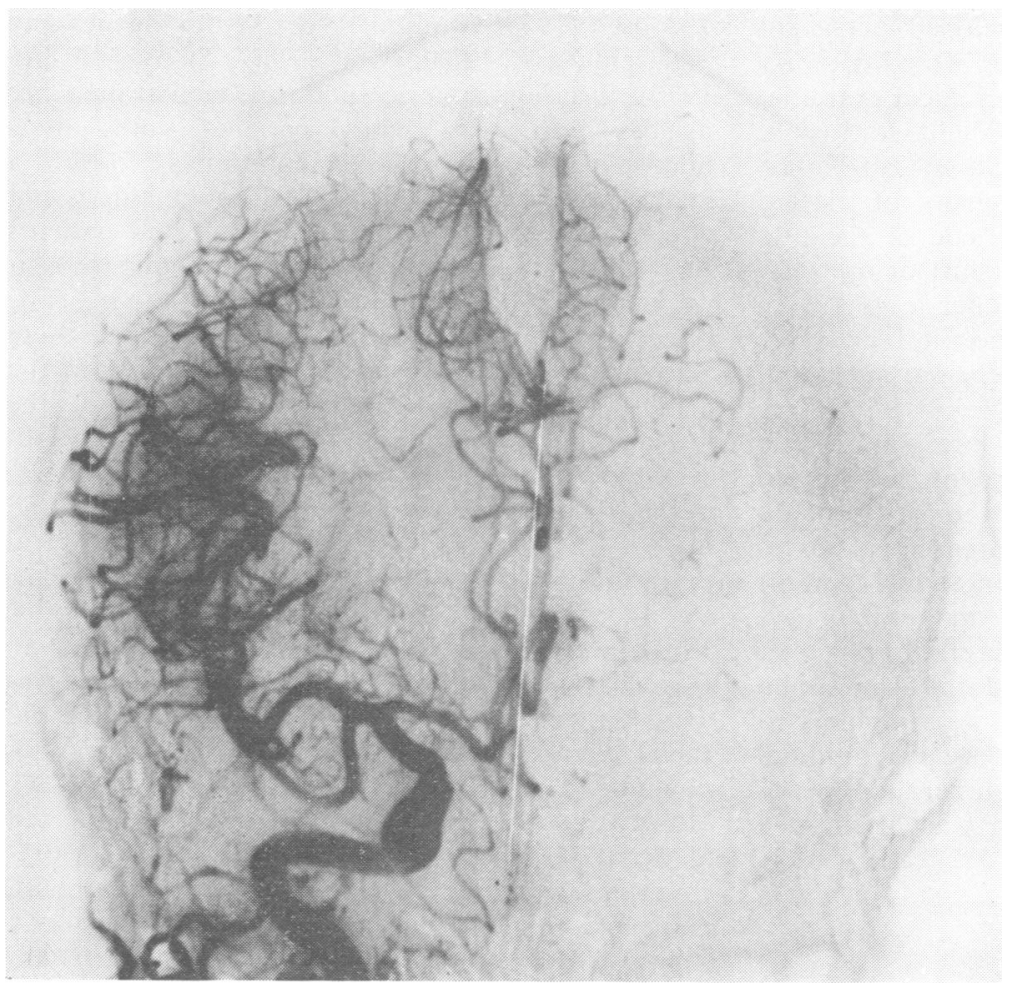

Fig. 1 Subtracted anteroposterior view of right carotid angiogram showing separation of right pericallosal arterial branches and supramarginal arteries from the midline by an avascular mass lying against the falx (case I).

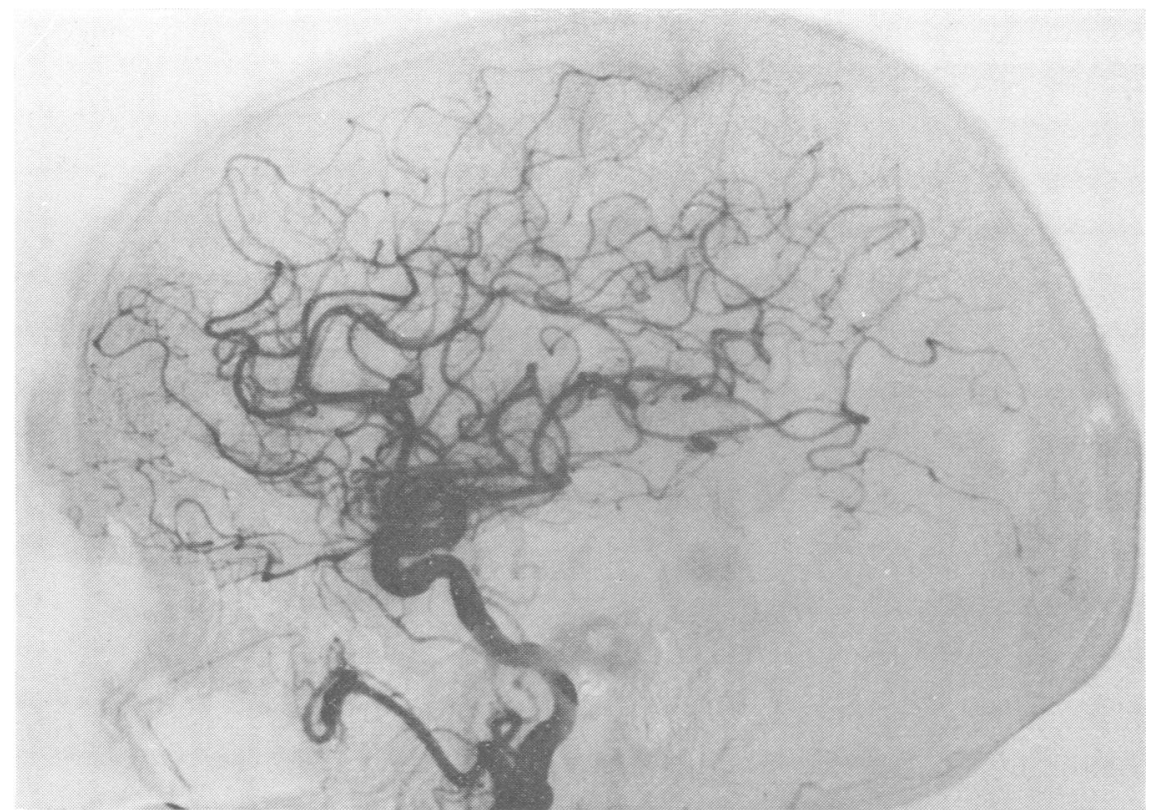

Fig. 2 Subtracted lateral view of right carotid angiogram showing depression of the pericallosal artery (case 1). 
out but several hours later developed persistent vertex headache. About four days after his injury he had a grand mal seizure. Neurological examination at one week revealed only slight confusion. Computerised tomography disclosed an interhemispheric mass having the density of clotted blood which lay against the left side of the falx (Fig. 3). There was a very slight shift of the midline structures to the right. No other lesions were evident. He was admitted to the hospital, and over the next few days his headache disappeared. Computerised tomography two weeks after injury showed partial resolution of the interhemispheric haematoma but a slight increase of the left to right shift. During the next week the patient again developed headache. A third computerised tomographic scan revealed an even larger left to right shift but no masses were seen. Angiography was performed and showed an extracerebral mass over the left hemisphere. A liquid subdural haematoma was removed through burr holes. A computerised scan one week after operation revealed minimal midline shift. A mild right postoperative hemiparesis cleared, and the patient was discharged 10 days after surgery.

\section{Discussion}

As shown by our two cases as well as seven of eight clinical reports (Aring and Evans, 1940;
Jacobsen, 1955; Gannon, 1961; Wollschlaeger and Wollschlaeger, 1964; Isfort, 1967; Sibayan et al., 1970), interhemispheric subdural haematomas are usually unilateral. Most patients with interhemispheric subdural haematomas have a characteristic clinical picture although this is not commonly realised. Of the five reported patients for whom sufficient description of hemiparesis is provided, four presented with dramatic paresis or seizures of the contralateral leg or both. In these four patients and in one of ours, weakness in the arm and face has been of much lesser degree (Aring and Evans, 1940; Jacobsen, 1955; Wollschlaeger and Wollschlaeger, 1964; Sibayan et al., 1970). The same clinical picture has been found in patients with interhemispheric subdural empyema (Keith, 1949; List, 1950, 1955; Kristiansen and Zimmer, 1958; Hitchcock and Andreadis, 1964; Patton and Hitchcock, 1968; Wilkins and Goree, 1970) and has been called the falx syndrome (List, 1955). In cases of subdural empyema, these symptoms have been ascribed to thrombophlebitis (Hitchcock and Andreadis, 1964). However, thrombophlebitis would not be expected to occur in cases of subdural haematoma. Moreover mass effect seen angiographically with $\stackrel{\circ}{\mathbb{D}}$ empyema is identical to that of interhemispheric subdural haematomas (List, 1950, 1955; Kristiansen and Zimmer, 1958; Hitchcock and Andreadis. 1964; Patton and Hitchcock, 1968; Wilkins and을

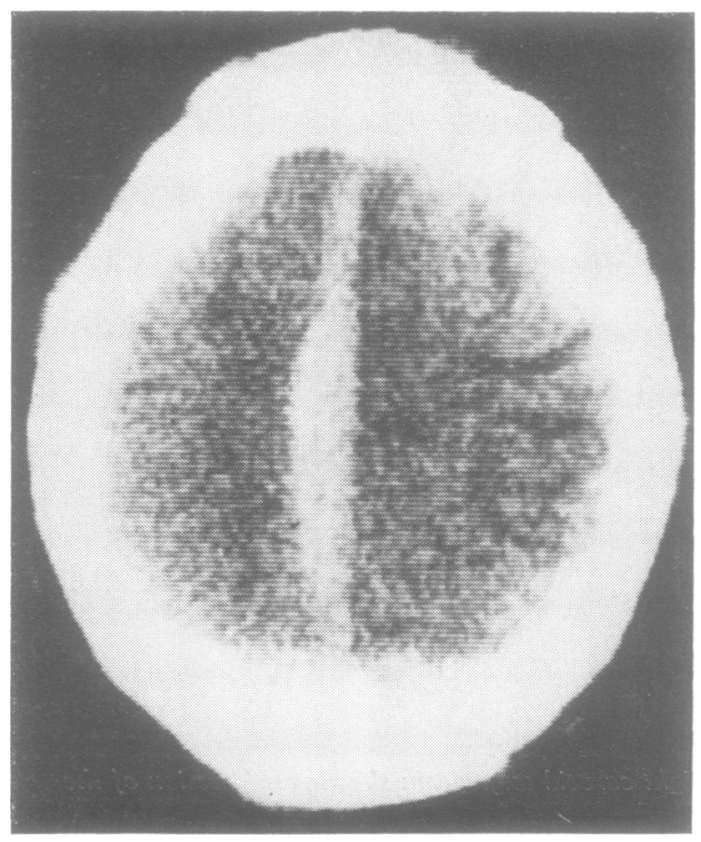

Fig. 3 Computerised tomogram one week after the injury showing a mass with the density of clotted blood lying along the left side of the falx (case 2). 
Goree, 1970). This suggests that both interhemispheric empyemas and subdural haematomas may produce the falx syndrome by virtue of their mass effect.

Both subdural haematomas and empyemas of the interhemispheric space appear to be quite uncommon. On the other hand, occlusion of an anterior cerebral artery is a much more frequent occurrence and also produces the clinical picture of the falx syndrome. For these reasons, we thought initially that our first patient probably had symptoms related to vascular insufficiency rather than a post-traumatic haematoma.

Our second case illustrates the possibility that occasional cases of chronic subdural haematomas of the convexity may originate as acute interhemispheric clot. The sequence of radiographic studies suggests that the initial clot was confined to the interhemispheric space whereas it was later limited to the space over the cerebral convexity. This possibility, that interhemispheric haematomas may move as they liquefy, may provide an alternative to early surgery. While removal of a solid clot from the interhemispheric space has proved to be successful, this can be a dangerous procedure due to the proximity of the sagittal sinus and bridging veins (Gannon, 1961). It is, therefore, conceivable that if a patient with an acute interhemispheric haematoma is relatively asymptomatic, initial conservative management might be followed by migration of the clot to a position over the convexity where removal is considerably less dangerous.

\section{References}

Aring. C. D.. and Evans. J. P. (1940). Aberrant location of subdural hematoma. Archives of Neurology and Psychiatry (Chicago), 44, 1296-1306.
Clein, L. J.. and Bolton, C. F. (1969). Interhemispheric subdural haematoma: a case report. Journal of Neurology, Neurosurgery, and Psychiatry, 32, 389392.

Gannon, W. E. (1961). Interhemispheric subdural hematoma, case report. Journal of Neurosurgery, $18,829-830$.

Hitchcock, E., and Andreadis. A. (1964). Subdural empyema: a review of 29 cases. Journal of Neurology, Neurosurgery, and Psychiatry, 27, 422434.

Isfort, A. (1967). Angiographische Befunde beim Hamatom und Empyem im Interhemispharenspalt. Fortschrifte auf dem Gebiete der Rontgenstrahlen, 107, 127-130.

Jacobsen, H. H. (1955). An interhemispherically situated haematoma, case report. Acta Radiologica. 43, 235-236.

Keith, W. S. (1949). Subdural empyema. Journal of Neurosurgery, 6, 127-139.

Kristiansen, K., and Zimmer, J. (1958). Interhemispheric subdural abscess. British Journal of Radiology, 31, 278-279.

List, C. F. (1950). Interhemispheric subdural suppuration. Journal of Neurosurgery, 7, 313-324.

List, C. F. (1955). Diagnosis and treatment of acute subdural empyema. Neurology (Minneapolis), 5, 663-670.

Patton, J. T., and Hitchcock, E. (1968). Angiographic features of falcine subdural empyema. Clinical Radiology, 19, 229-232.

Sibayan, R. Q., Gurdjian, E. S., and Thomas, L. M. (1970). Interhemispheric chronic subdural hematoma, report of a case. Neurology (Minneapolis), 20, $1215-1218$.

Wilkins, R. H., and Goree, J. A. (1970). Interhemispheric subdural empyema: angiographic appearance. Journal of Neurosurgery, 32, 459-462.

Wollschlaeger, P. B., and Wollschlaeger, G. (1964). The interhemispheric subdural or falx hematoma. American Journal of Roentgenology, 92, 12521254. 